\title{
Effect of Chromium on the Corrosion Behavior of Powder-Processed Fe-0.6 wt\% P Alloys
}

\author{
Yashwant Mehta ${ }^{*}$, Shefali Trivedi, K. Chandra, P. S. Mishra \\ Indian Institute of Technology, Roorkee, Uttarakhand, India \\ Email: *yashwant.mehta@gmail.com
}

Received June 7, 2012; revised August 18, 2012; accepted September 11, 2012

\begin{abstract}
Phosphoric irons (i.e. Fe-P alloys containing low phosphorous in the range 0.1 to $0.7 \mathrm{wt} \%$ ) with/without addition of chromium were prepared by powder forging route. The corrosion behaviour of these alloys was studied in different environments. The various environments chosen were acidic $\left(0.25 \mathrm{M} \mathrm{H}_{2} \mathrm{SO}_{4}\right.$ solution of $\left.\mathrm{pH} 0.6\right)$, neutral/marine $(3.5 \%$ $\mathrm{NaCl}$ solution of $\mathrm{pH} 6.8)$ and alkaline $\left(0.5 \mathrm{M} \mathrm{Na}_{2} \mathrm{CO}_{3}+1.0 \mathrm{M} \mathrm{NaHCO}_{3}\right.$ solution of $\left.\mathrm{pH} 9.4\right)$. The corrosion studies were conducted using Tafel Extrapolation and Linear Polarization techniques. The results were compared with the corrosion resistance of electrolytic Armco iron. It was observed that, chromium improved the resistance to corrosion in marine conditions only. Corrosion rates were higher in acid medium due to the enhanced hydrogen evolution and hence, the cathodic reaction. The corrosion rates were minimal in alkaline medium and low in neutral solution.
\end{abstract}

Keywords: Phosphoric Iron; Alloy; Polarization; Acid Corrosion; Alkaline Corrosion

\section{Introduction}

Vera et al. reported that corrosion attack on plain carbon steel is more severe in a marine environment than in urban and rural media [1]. Fontana opines that corrosion of iron or steel is affected by environment [2]. Lorbeer and Lorenz found that corrosion depends on both, the composition of the metal/alloy and the environmental conditions. Important electrolyte variables affecting corrosion of iron are $\mathrm{pH}$, concentration, fluid flow, temperature and oxidizing power of the solution [3]. Oxygen reduction predominates in weak acid and neutral solutions. Corrosion rate depends on hydrogen ion concentration in case of acidic solutions [3]. The addition of Chromium increased the atmospheric corrosion resistance in all the cases studied by Hudson and Stanners [4]. Segregation of phosphorus to grain boundaries can strongly affect intergranular stress corrosion cracking (SCC) of irons and steels in carbonate/bicarbonate solutions. This was reported by Parkins for irons [5] and Stencel et al. for steels [6]. Cleary and Greene said that phosphorus additions reduced alloy corrosion resistance and chromium did not affect the behaviour in de-aerated $0.1 \mathrm{~N}$ sulphuric acids [7].

Balasubramaniam writes that ancient phosphoric irons that were used for constructing large beams and located at Konark and Puri in India, have revealed excellent atmospheric corrosion resistance in saline seashore environments for several hundred years. The 1600-year-old

${ }^{*}$ Corresponding author.
Delhi Iron Pillar displays exemplary corrosion resistance. The presence of $0.25 \mathrm{wt} \%$ phosphorus in the Pillar facilitates the formation of a protective passive film on the surface and thus provides excellent corrosion resistance to it $[8,9]$. Sahoo and Balasubramaniam found that $\mathrm{Cr}$ and $\mathrm{Cu}$ containing low alloy steel will be suitable for application in an acidic environment while alloying steel with phosphorus is not beneficial in such an environment [10].

An attempt therefore needs to be made to understand the role of chromium in carbon-free phosphoric irons. In this paper, the corrosion behavior of two powder metallurgy based phosphoric irons with $0.00 \mathrm{wt} \% \mathrm{C}$ alloyed with/without chromium has been investigated in three different solutions.

\section{Experimental}

Iron powder (Fe-99.99 wt\%, C-0.00 wt\%; -200 mesh) was mixed with iron-phosphide (C-0.00 wt \%; -200 mesh), low carbon ferro-chromium ( $\mathrm{C}<0.01 \mathrm{wt} \% ;-200$ mesh) to make the alloys by powder metallurgy. Iron and low carbon ferro-chromium powders were of commercial purity. Iron phosphide powder was prepared by mixing iron powders with ortho-phosphoric acid. The procedure of preparing iron-phosphide powder is described elsewhere [11]. Two powder metallurgical alloys were made in the present investigation. Their compositions are given in Table 1. The compositions of these alloys are based on the powder mixture. The process of making slabs by hot powder forging technique is explained elsewhere [11]. 
Table 1. Composition of phosphoric irons developed in the study \& Armco iron.

\begin{tabular}{cccc}
\hline Sample & $\mathrm{P}(\mathrm{wt} \%)$ & $\mathrm{Cr}(\mathrm{wt} \%)$ & $\mathrm{Fe}$ \\
\hline 1 (Armco) & - & - & $>99 \%$ \\
2 & 0.6 & - & Balance \\
3 & 0.6 & 4 & Balance \\
\hline
\end{tabular}

Samples for corrosion testing were prepared as detailed elsewhere [11]. The samples were mounted in a K0047 Corrosion Cell (used in ASTM standard G-5, supplied by Ametek, USA) for conducting Tafel polarization studies at a scan rate of $0.166 \mathrm{mV} / \mathrm{s}$. The Tafel extrapolation method (conducted as per ASTM Standard G3-89 [12]) was utilized for determining $\mathrm{i}_{\text {corr }}$ of the phosphoric irons and Armco electrolytic iron in 3.5\% $\mathrm{NaCl}$ having $\mathrm{pH}$ 6.8. Since the cathodic reaction was primarily diffusion controlled in the case of $3.5 \% \mathrm{NaCl}$ solution having $\mathrm{pH} 6.8$, the activation-controlled anodic Tafel region was extrapolated to intersect the horizontal drawn at zero current potential to obtain the corrosion rate as per ASTM Standard G102-89 [13].

Linear Polarization technique was used to evaluate the corrosion rates of the phosphoric irons in $0.5 \mathrm{M} \mathrm{Na}_{2} \mathrm{CO}_{3}$ $+1.0 \mathrm{M} \mathrm{NaHCO}_{3}$ solution of $\mathrm{pH}$ 9.4. A scan rate of $0.166 \mathrm{mV} / \mathrm{s}$ was used. Corrosion rate in penetration units (like mils/year, mpy), was calculated from $\mathrm{i}_{\text {corr }}$ using the following equation used by Ijselling [14]:

where $\Lambda=1.2866 \times 10^{5}$

$$
\text { mpy }=\mathrm{i}_{\text {corr }} \times \Lambda \times 1 / \rho \times \varepsilon
$$

(equivalents $\cdot \mathrm{s} \cdot \mathrm{mil}) /($ Coulombs $\cdot \mathrm{cm} \cdot$ years),

$i_{\text {corr }}=$ the corrosion current density in Amps $/ \mathrm{cm}^{2}$ (Amp

$=1$ Coulomb $/ \mathrm{s})$,

$\rho=\operatorname{density}\left(7.86 \mathrm{~g} / \mathrm{cm}^{3}\right.$, for iron),

$\varepsilon=$ equivalent weight ( $27.56 \mathrm{~g} /$ equivalent, for iron).

The solutions were prepared using chemicals of analytical grade reagent and single distilled water. A digital pH meter (Phillips, model 9045) was used for recording $\mathrm{pH}$ of the solutions at room temperature. The $\mathrm{pH}$ meter was calibrated using three different standard $\mathrm{pH}$ solutions before recording $\mathrm{pH}$.

An EG and G PARSTAT 273A Potentiostat (Ametek, USA) and a saturated calomel reference electrode (SCE) were used in all electrochemical experiments. The open circuit potential (OCP) was stabilized for $1 \mathrm{hr}$ before the start of each experiment. All the experiments were repeated three times.

\section{Results and Discussion}

The corrosion rates determined by the Tafel extrapolation method in aerated solution of $0.25 \mathrm{M} \mathrm{H}_{2} \mathrm{SO}_{4}$ of $\mathrm{pH} 0.6$ and $3.5 \% \mathrm{NaCl}$ of $\mathrm{pH} 6.8$ and those determined by the linear polarization method in aerated solutions of $0.5 \mathrm{M}$ $\mathrm{Na}_{2} \mathrm{CO}_{3}+1.0 \mathrm{M} \mathrm{NaHCO}_{3}$ of $\mathrm{pH} 9.4$ are discussed sepa- rately below. Flitt and Schweinsberg said that the cathodic reaction for the samples obtained in all the three solutions discussed above consists of a composite reaction of [15] hydrogen evolution

$$
2 \mathrm{H}^{+}+2 \mathrm{e}^{-} \rightarrow \mathrm{H}_{2}, 2 \mathrm{H}_{2} \mathrm{O}+2 \mathrm{e}^{-} \rightarrow \mathrm{H}_{2}+2 \mathrm{OH}^{-}
$$

and oxygen reduction

$$
1 / 2 \mathrm{O}_{2}+\mathrm{H}_{2} \mathrm{O}+2 \mathrm{e}^{-} \rightarrow 2 \mathrm{OH}^{-}
$$

This is also evident from Pourbaix diagram of the $\mathrm{Fe}-\mathrm{H}_{2} \mathrm{O}$ system.

\subsection{Tafel Extrapolation Method}

\subsection{5 $\mathrm{M} \mathrm{H}_{2} \mathrm{SO}_{4}$ Solution (pH 0.6)}

As $\mathrm{pH}$ decreases, hydrogen evolution rate tends to dominate over oxygen reduction rate at $\mathrm{E}_{\text {corr }}$. Therefore, at $\mathrm{pH}$ 0.6 , the contribution of hydrogen evolution at $\mathrm{E}_{\text {corr }}$ is noteworthy. The exchange current density $i_{0}$ for hydrogen evolution $\mathrm{H}^{+} / \mathrm{H}_{2}$ and $\mathrm{i}_{\text {corr }}$ increase on increasing the concentration of $\mathrm{H}^{+}$ion or decreasing the $\mathrm{pH}$ [16]. Hence corrosion rate increases.

The $\mathrm{E}_{\text {corr }}, \mathrm{i}_{\text {corr }}$ and corrosion rate (mpy) obtained from the Tafel curves of the samples are tabulated in Table 2 and displayed in Figure 1.

The $\mathrm{E}_{\text {corr }}$ lies between $-471 \mathrm{mV}_{\mathrm{SCE}}$ and $-511 \mathrm{mV}_{\mathrm{SCE}}$. The corrosion rate for sample 2 is $152 \mathrm{mpy}$. This is less than that obtained for plain carbon steel (250 mpy) [10]. The corrosion rate for sample 3 is 1044 mpy.

Table 2. Corrosion data (Tafel) for Phosphoric irons in $\mathbf{0 . 2 5}$ $\mathrm{M} \mathrm{H}_{2} \mathrm{SO}_{4}$ solution (0.6 pH).

\begin{tabular}{cccc}
\hline Sample & $\mathrm{E}_{\text {corr }}$ vs SCE $(\mathrm{mV})$ & $\mathrm{I}_{\text {corr }}(\mu \mathrm{A})$ & Corrosion Rate $(\mathrm{mpy})$ \\
\hline 1 & -553.0 & 174.7 & 78.8 \\
2 & -511.7 & 338.6 & 152.75 \\
3 & -471 & 2315 & 1044.36 \\
\hline
\end{tabular}

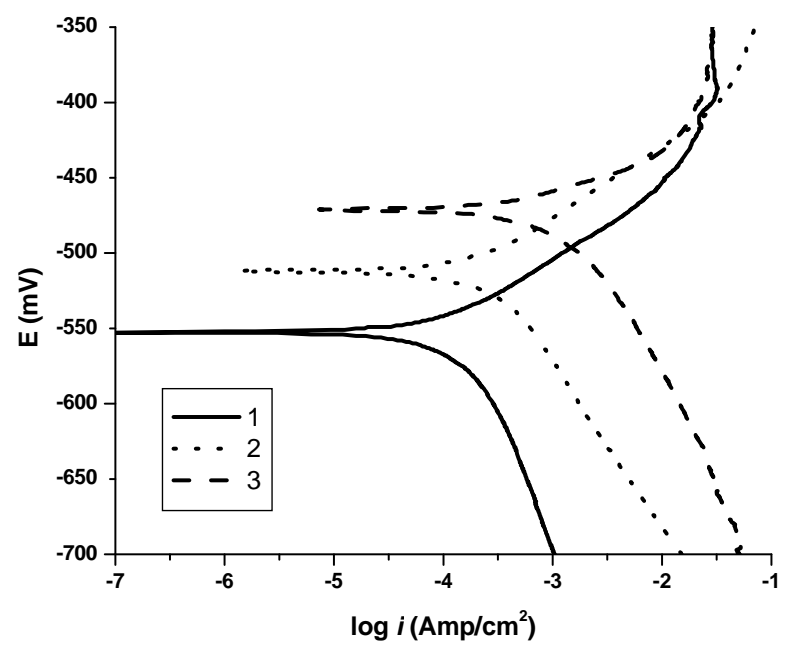

Figure 1. Tafel curves for Phosphoric irons in $0.25 \mathrm{M}$ $\mathrm{H}_{2} \mathrm{SO}_{4}$ solution (0.6 pH). 


\subsubsection{5\% NaCl Solution (pH 6.8)}

The Tafel plots obtained in aerated $3.5 \% \mathrm{NaCl}$ solution are shown in Figure 2. In this case, the diffusion controlled oxygen reduction reaction is the dominant reaction at $\mathrm{E}_{\text {corr }}$ [15].The $\mathrm{E}_{\text {corr }}, \mathrm{i}_{\text {corr }}$ and corrosion rate (mpy) obtained from the Tafel polarization curves of samples (Figure 2) are tabulated in Table 3.

The corrosion rate was obtained from the Tafel extrapolation method matched with literature data, as discussed below. The corrosion rate of iron is $12 \mathrm{mpy}$ as obtained by McCafferty using the Tafel extrapolation method after 24 hours of immersion in unstirred, air saturated 3.5\% $\mathrm{NaCl}$ solution [17]. Dexter reports that the actual corrosion rate of plain carbon steel (AISI 1020 steel) in quiet surface water is up to $15 \mathrm{mpy}$ in the first year and then decreases to 5 mpy after 1000 days [18]. The $\mathrm{E}_{\text {corr }}$ of the samples lies between $-600 \mathrm{mV}_{\mathrm{SCE}}$ and $-690 \mathrm{mV}_{\text {SCE }}$. The corrosion rate of samples obtained by the Tafel extrapolation method after $1 \mathrm{~h}$ immersion in $3.5 \% \mathrm{NaCl}$ was in the range of 6 to $10 \mathrm{mpy}[10]$.

In the present study, the corrosion rate of samples obtained by the Tafel extrapolation method after $1 \mathrm{~h}$ immersion in $3.5 \% \mathrm{NaCl}$ was in the range of 1.3 to $7 \mathrm{mpy}$. The $\mathrm{E}_{\text {corr }}$ of the samples lies between $-619 \mathrm{mV}_{\mathrm{SCE}}$ and $-633 \mathrm{mV}_{\text {SCE. }}$

\subsection{Linear Polarization method}

\subsubsection{5 $\mathrm{M} \mathrm{Na}_{2} \mathrm{CO}_{3}+1.0 \mathrm{M} \mathrm{NaHCO}_{3}$ Solution (pH 9.4)}

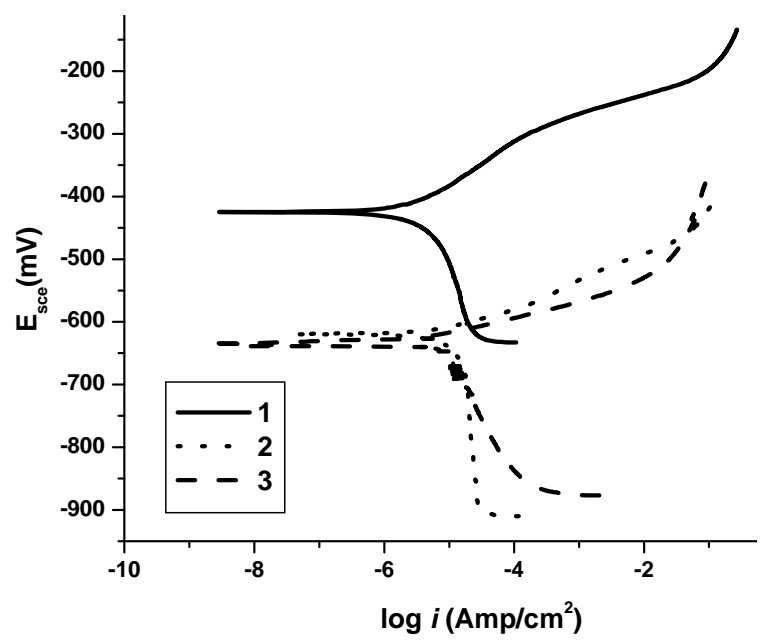

Figure 2. Tafel curves for phosphoric irons in $3.5 \% \mathrm{NaCl}$ solution (6.8 pH).

Table 3. Corrosion data (Tafel) for phosphoric irons in $3.5 \% \mathrm{NaCl}$ solution $(6.8 \mathrm{pH})$.

\begin{tabular}{cccc}
\hline Sample & $\mathrm{E}_{\text {corr }}$ vs SCE $(\mathrm{mV})$ & $\mathrm{I}_{\text {corr }}(\mu \mathrm{A})$ & Corrosion Rate $(\mathrm{mpy})$ \\
\hline 1 & -424.6 & 2.897 & 1.3 \\
2 & -619.8 & 15.60 & 7.03 \\
3 & -633.8 & 2.958 & 1.33 \\
\hline
\end{tabular}

This solution was chosen to evaluate the corrosion resistance of the samples against soil (buried condition). Sikora et al. reported that alkaline solutions are known to cause intergranular SCC due to segregation of Phosphorous in low alloy steels, [19].

The $\mathrm{E}_{\text {corr }}, \mathrm{i}_{\text {corr }}$ and corrosion rate (mpy) obtained from the linear polarization curves of samples are tabulated in Table 4 and displayed in Figures 3(a)-(c). The $\mathrm{E}_{\text {corr }}$ lies between $-250 \mathrm{mV}_{\mathrm{SCE}}$ and $-262 \mathrm{mV}_{\mathrm{SCE}}$. The corrosion rate is low and lies between 0.9 - 38 mpy (mils per year). The second composition can be used in buried (in soil) conditions.

\subsection{Segregation of Alloying Elements}

Powder metallurgical phosphoric irons developed in the present investigation are free of any segregation of the alloying elements along the grain boundaries. They get distributed uniformly in the entire structure. This has been confirmed by:

- Optical Microscope (Figure 4),

- Surface Morphology (SEM) and EDAX Pattern from different Spots (Figures 5(a) and (b)),

- Composition Image [Secondary Image] and X-Ray Mapping (Figure 6).

The optical micrographs show that the pores are elongated in the direction of rolling. The pores are found predominantly in the interior of the grains. The pores appear larger than their actual size due to the effect of etching. All the grains belong to a single phase that is ferrite. No other phase can be detected.

The SEM photos reveal that the grains are of a single phase. There is no second phase. The pores are away from the grain boundaries which is good for the mechanical properties. The microstructures are very similar. This is because the two compositions differ from each other marginally i.e. by $4 \% \mathrm{Cr}$.

The analysis of surface morphology and EDAX pattern from different spots reveals that the elements are distributed more or less evenly in the grain interiors and at the grain boundaries. This data should not be interpreted in the absolute sense. They can be utilized for comparison purposes, at best.

$\mathrm{Cr}$ and $\mathrm{P}$ are ferrite stabilizers. When the mixture of powders is subjected to consolidation, employing high temperature and pressure, it will undergo phase transformation. Fe powder particles would first convert to

Table 4. Corrosion data (linear polarization) for phosphoric irons in $0.5 \mathrm{M} \mathrm{Na}_{2} \mathrm{CO}_{3}+1.0 \mathrm{M} \mathrm{NaHCO}$ solution (9.4 pH).

\begin{tabular}{cccc}
\hline Sample & $\mathrm{E}_{\text {corr }}$ vs SCE $(\mathrm{mV})$ & $\mathrm{I}_{\text {corr }}(\mu \mathrm{A})$ & Corrosion Rate $(\mathrm{mpy})$ \\
\hline 1 & -252 & 0.2424 & 0.11 \\
2 & -262.4 & 2.061 & 0.93 \\
3 & -250.8 & 84.85 & 38.28 \\
\hline
\end{tabular}




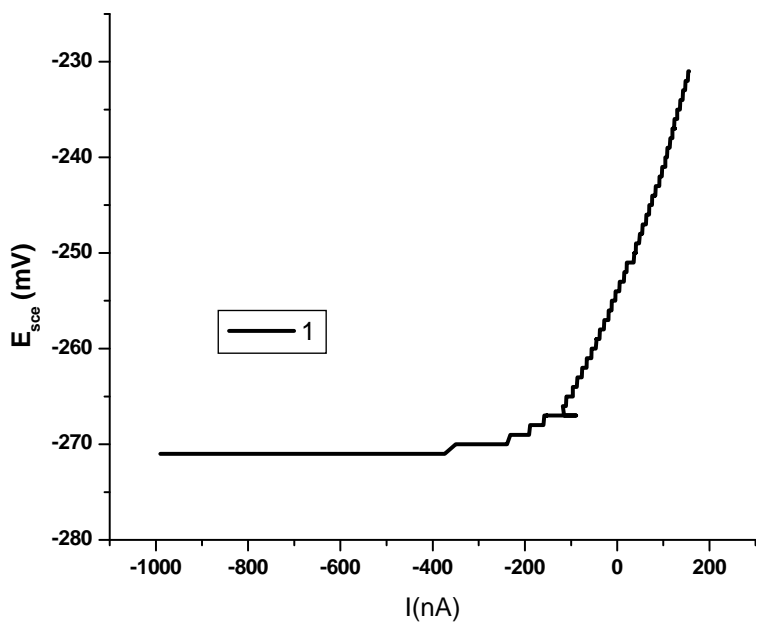

(a)

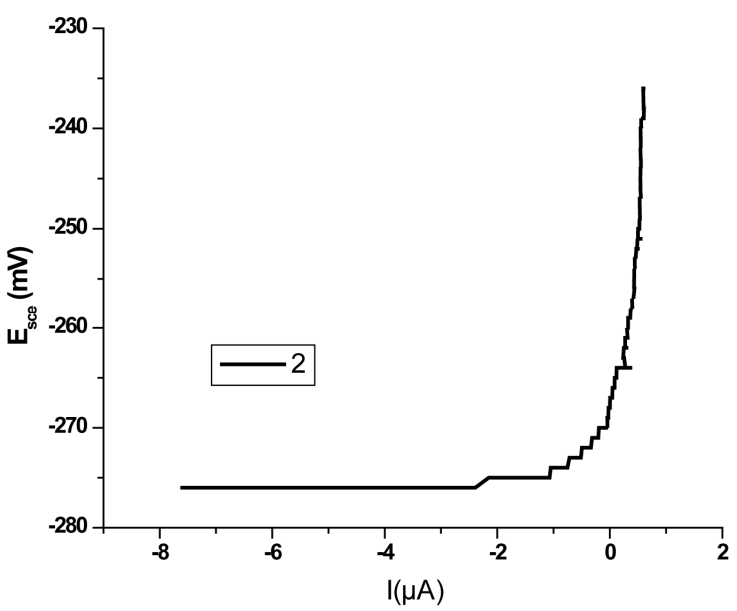

(b)

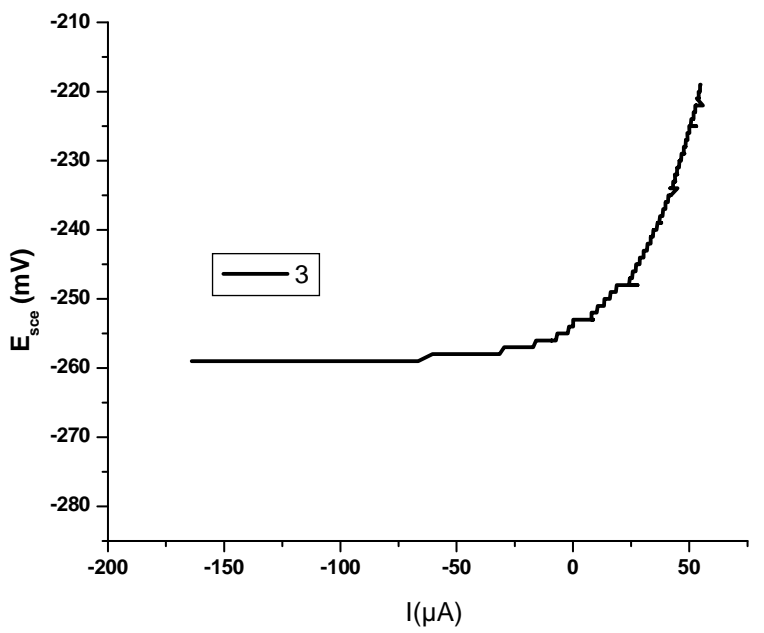

(c)

Figure 3. (a) Linear polarization curves for the sample 1 in $0.5 \mathrm{M} \mathrm{Na}_{2} \mathrm{CO}_{3}+1.0 \mathrm{M} \mathrm{NaHCO}_{3}$ solution (9.4 pH); (b) linear polarization curves for the sample 2 in $0.5 \mathrm{M} \mathrm{Na}_{2} \mathrm{CO}_{3}+1.0$ $\mathrm{M} \mathrm{NaHCO}$ solution (9.4 pH); (c) linear polarization curves for the sample 3 in $0.5 \mathrm{M} \mathrm{Na}_{2} \mathrm{CO}_{3}+1.0 \mathrm{M} \mathrm{NaHCO}_{3}$ solution (9.4 pH).

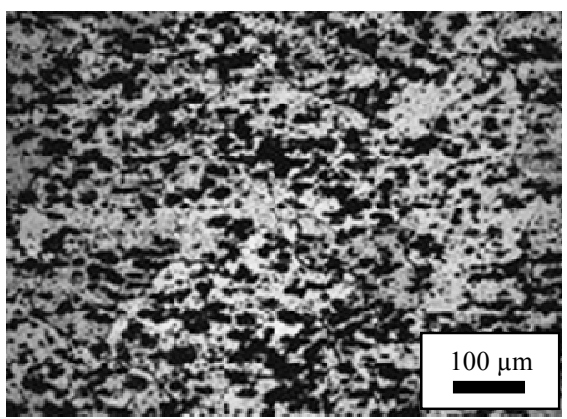

(a)

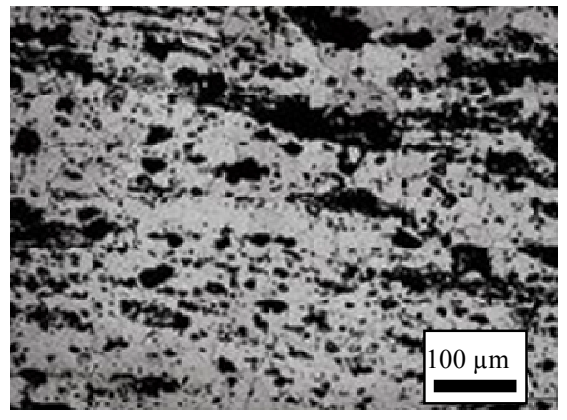

(b)

Figure 4. Microstructures of rolled and anne-a-led alloys etched with $2 \%$ Nital. Pores are elongated in the rolling direction. (a) Sample 2 \& (b) Sample 3.

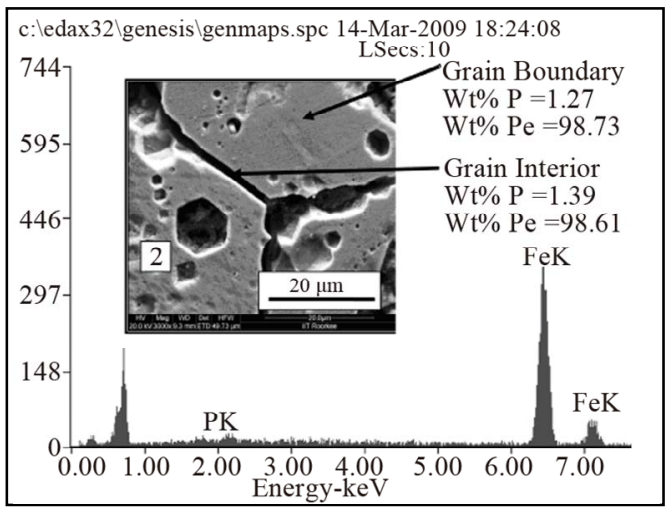

(a)

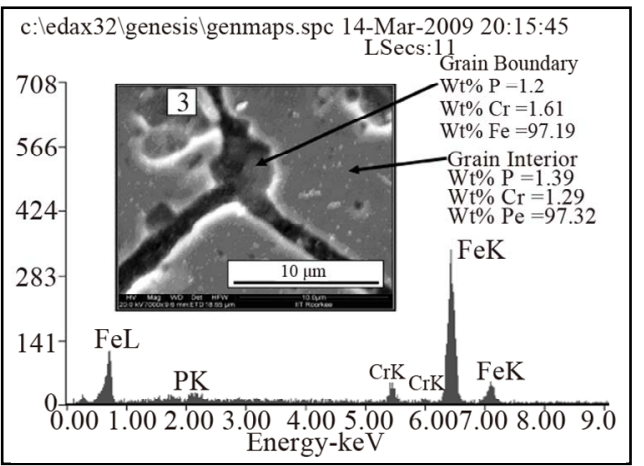

(b)

Figure 5. (a), (b), Surface morphology and EDAX pattern from different spots on samples 2 and 3. 


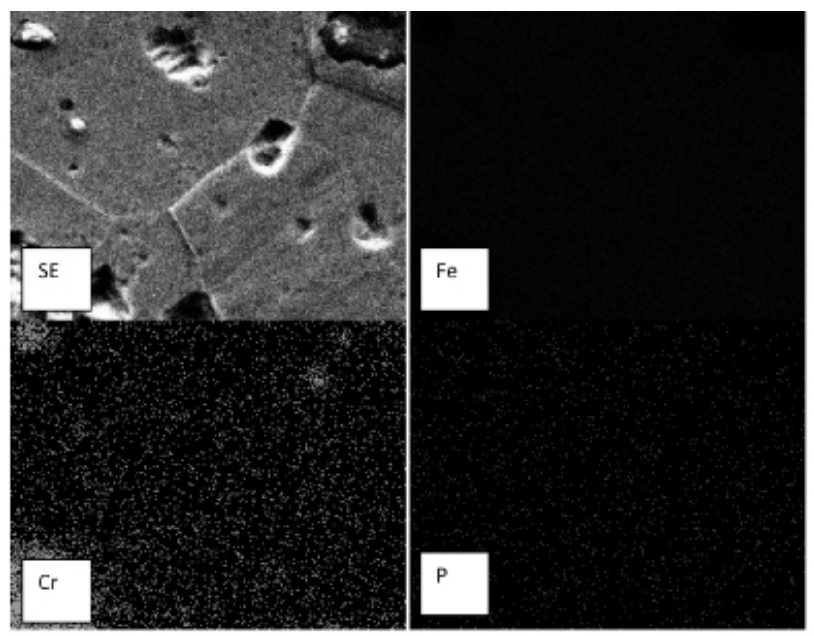

Figure 6. Composition image [secondary image] \& X-ray mapping of sample 3 .

gamma (FCC) iron and as ferrite stabilizers diffuse inside, they would gradually convert into alpha (BCC) iron. In this way, transfer of all the ferrite stabilizers would proceed from Fe particle surfaces towards the interior of the particles. The grain boundaries and grain interiors do not show any major differences in the concentration of $\mathrm{P}$ with/without chromium. Further, Briant found that the segregation of phosphorus is not affected by changes in the amounts of $\mathrm{Ni}, \mathrm{Cr}$, and $\mathrm{Mn}$ in the steel [20].

$\mathrm{X}$-ray mapping of all the elements confirms that these elements get distributed uniformly in the entire structure showing no signs of segregation, of any alloying element.

Furthermore, both the samples had the same amount of residual porosity i.e. about $7 \mathrm{vol} \%$. Hence they can be compared with each other.

\section{Conclusions}

1) Ordinarily, Powder metallurgical alloys are poor in corrosion resistance due to the inherent porosity associated with them. However, Phosphoric Irons alloyed with ferrite formers such as silicon, offer improved corrosion resistance in general, as compared with known wrought based iron systems.

2) Chromium addition in Iron-Phosphorous powder metallurgical alloys lower corrosion rates at $6.8 \mathrm{pH}$.

3) The compositions designed in this investigation are preferable under coastal/marine/de-icing salt conditions.

The second alloy can also be used under alkaline conditions.

\section{Acknowledgements}

We are grateful an anonymous referee for helpful comments. We also wish to thank Kim Humphreys for English editing. All errors are ours.

\section{REFERENCES}

[1] R. Vera, B. Rosales and C. Tapia, "Effect of the Exposure Angle in the Corrosion Rate of Plain Carbon Steel in a Marine Atmosphere," Corrosion Science, Vol. 45, No. 2, 2003, pp. 321-337. doi:10.1016/S0010-938X(02)00071-9

[2] M. G. Fontana and Greene, "Corrosion Engineering," 3rd Edition, McGraw-Hill International Edition, 2006, pp. 23-27,499-503.

[3] P. Lorbeer and W. J. Lorenz, "The Kinetics of Iron Dissolution and Passivation in Solutions Containing Oxygen," Electrochimica Acta, Vol. 25, No. 4, 1980, pp. 375381. doi:10.1016/0013-4686(80)87026-5

[4] J. C. Hudson and J. F. Stanners, "The Corrosion Resistance of Low-Alloy Steels," Journal of the Iron and Steel Institute, Vol. 180, 1955, pp. 271-284.

[5] R. N. Parkins, "Environment-Induced Cracking of Metals," NACE, Houston, 1990.

[6] H. Stencel, H. Vehoff and P. Neumann, "Chemistry and Physics of Fracture,” Martinus Nijhoff, Dordrecht, 1987, p. 652. doi:10.1007/978-94-009-3665-2 40

[7] H. J. Cleary and N. D. Greene, "Corrosion Properties of Iron and Steel," Corrosion Science, Vol. 7, No. 12, 1967, pp. 821-831. doi:10.1016/S0010-938X(67)80115-X

[8] R. Balasubramaniam, "On the Corrosion Resistance of the Delhi Iron Pillar," Corrosion Science, Vol. 42, No. 12, 2000, pp. 2103-2129. doi:10.1016/S0010-938X(00)00046-9

[9] R. Balasubramaniam and A. V. Ramesh Kumar, "Characterization of Delhi Iron Pillar Rust by X-Ray Diffraction, Fourier Infrared Spectroscopy, Mössbauer Spectroscopy," Corrosion Science, Vol. 42, No. 12, 2000, pp. 2085-2101. doi:10.1016/S0010-938X(00)00045-7

[10] G. Sahoo and R. Balasubramaniam, "Corrosion of Phosphoric Irons in Acidic Environments," Journal of ASTM International, Vol. 5, No. 5, 2008, pp. 1-7.

[11] Y. Mehta, S. Trivedi, K. Chandra and P. S. Mishra, "Effect of Chromium on the Corrosion Behavior of PowderProcessed Fe-0.35 wt\% P Alloys," Journal of Minerals \& Materials Characterization \& Engineering, Vol. 8, No. 7, 2009, pp. 501-511.

[12] ASTM Standard G3-89, "Standard Practice for Conventions Applicable to Electrochemical Measurements in Corrosion Testing," Annual Book of ASTM Standards, ASTM International, West Conshohocken, Vol. 3.02; 2006.

[13] ASTM Standard G102-89, "Standard Practice for Calculation of Corrosion Rates and Related Information from Electrochemical Measurements," Annual Book of ASTM Standards, ASTM International, West Conshohocken, Vol. 3.02, 2006.

[14] F. P. Ijsseling, "Application of Electrochemical Methods of Corrosion Rate Determination to System Involving Corrosion Product Layers," British Corrosion Journal, London, Vol. 21, 1986, pp. 95-101.

[15] H. J. Flitt and D. Schweinsberg, "Evaluation of Corrosion Rate from Polarization Curves Not Exhibiting a Tafel Region," Corrosion Science, Vol. 47, No. 12, 2005, pp. 
3034-3052. doi:10.1016/j.corsci.2005.06.014

[16] A. Davydov, V. Rybalka, L. Beketaeva, G. Engelhardt, P. Jayaweera and D. Macdonald, "The Kinetics of Hydrogen Evolution and Oxygen Reduction on Alloy 22," Corrosion Science, Vol. 47, No. 1, 2005, pp. 195-215. doi:10.1016/j.corsci.2004.05.005

[17] E. McCafferty, "Validation of Corrosion Rates Measured by the Tafel Extrapolation Method," Corrosion Science, Vol. 47, No. 12, 2005, pp. 3202-3215. doi:10.1016/j.corsci.2005.05.046

[18] S. C. Dexter, "Handbook of Oceanographic Engineering
Materials," John Wiley and Sons, New York, 1979, p. 111.

[19] E. Sikora, A. Sadkowski and J. Flis, "Impedance Study of Effect of Phosphorus on Anodic Behavior of Iron in Carbonate/Bicarbonate Solutions," Electrochimica Acta, Vol. 38, No. 16, 1993, pp. 2443-2447. doi:10.1016/0013-4686(93)85114-E

[20] C. L. Briant, "The Effect of Nickel, Chromium, and Manganese on Phosphorus Segregation in Low Alloy Steels," Scripta Metallurgica, Vol. 15, No. 9, 1981, pp. 10131018. doi:10.1016/0036-9748(81)90245-3 